an examination of Hill's and Lamé's equation, and allied equations, in the scond half. It is difficult to think of any alternative souree in English which renders this somewhat recalcitrant material so readily accessible. The author in his preface suggests that Lamé's and allied functions might afford a superior means of solving the boundary- and initial-value problems of mathematical physics than computer supplied numerical solutions. Certainly no mathematician would attempt a numerical solution if moderately tractable analytical machinery were available, but Arscott's own model example on pp. 228 et seq. shows how far this is from being the ease for even the simplest problems relating to ellipsoidal domains. If a practical motivation for studying the higher functions must be cited, it ought to be that their Frobenius or asymptotic expansions reveal the approximate structure of potentials and waves at important special neighbourhoods beyond numerical scope.

The book by van der Pol (now deceased) and Bremmer is the second impression of the 1959 edition of their wellknown text. Its suecess stems not merely from their treatment of the operational calculus, but also from their refreshing approach to various important modern infinitesimal processes. For example, their remarks on Stieltjes integration make clear just why such an integral should be introduced and what kind of part it could use. fully play. An appreciation of this factor is, for most students, the critical step on learning any new technique. Although primarily addressed to applied mathematicians, and mathematically minded physicists and engineers, it contains much of interest to mathematical analysts. Historical aspects are not overlooked, and it comes as no surprise to find that Dirac's delta function had been extensively used by Oliver Heaviside. A confusing notational mishap occurs on p. 7, where the same symbol, used in different senses, appears in both the Fourier series and Fourier integral.

M. A. JASWON

\section{MATHEMATICAL TABLES FROM THE U.S.S.R.}

Mathematical Tables Series

Volume 23. Tables of the Function

$$
F(z)=\int_{0}^{z} \mathrm{e}^{x 2} \mathrm{~d} x
$$

in the Complex Form. By K. A. Karpov. Translated by D. E. Brown. Pp. $\mathrm{xxv}+497$. 140s. net.

Volume 27. Tables of the Function

$$
w(z)=e^{-z 2} \int_{0}^{z} e^{x 2} \mathrm{~d} x
$$

in the Complex Domain. By K. A. Karpov. Translated by D. E. Brown. Pp. xxi+519. 140s. net.

Volume 37. Tables of Elliptical Integrals, Part 1. By V. M. Belyakov, P. I. Kravtsova and M. G. Rappoport. Pp. xiii +647 . 140s. net.

Volume 38. Tables of the Legendre Functions, Part 2. By M. I. Zhurina and L. N. Karmazina. Translated by Prasenjit Basu. Pp. xiii +409 . 120s. net.

(London and New York: Pergamon Press, 1964 and 1965.)

7 HESE volumes of Russian tables, which are supplied with an English translation of the introductory matter, wore printed in Poland. The pages are generally clean, without too many rules, and the old-style fount is pleasant and legible, though the slightly exaggerated "heads and tails" occasionally make for a crowded appearance when the setting is close. Differences are not printed.

Volumes 23 and 27 deal with the error integral for a complex argument in polar form, $z=\rho \exp (i \theta)$, in each case giving the real and imaginary parts of the function at ain opening to five dycimals. In Volume 23 the range of $\theta$ is $45^{\circ}\left(0^{\circ} \cdot 3125\right) 48^{\circ} \cdot 75\left(0^{\circ} \cdot 625\right) 55^{\circ}\left(1^{\circ} \cdot 25\right) 65^{\circ}\left(2^{\circ} \cdot 5\right) 90^{\circ}$ and the range of $\rho$ depends on $\theta$ with a lower limit of $0,0.5,1,1 \cdot 5,2,3 \cdot 5$ or 4 and an upper limit of 3,4 or 5 , at intervals of 0.001 or 0.01 . A subsidiary table gives $F$ for real $z(\theta=0), p=0(0.001) 10$. Volume 27 was compiled in connexion with a problem on the propagation of radio waves, and supplies information for the ranges:

$$
\begin{aligned}
& \theta=0^{\circ}, \rho=0(0.001) 2(0.01) 10 ; \\
& \theta=0\left(2 \cdot 5^{\circ}\right) 30^{\circ}\left(1.25^{\circ}\right) 35^{\circ}\left(0.625^{\circ}\right) 45^{\circ},
\end{aligned}
$$

where has an uppor limit 5 , a lower limit, depending on $\theta$, between 0 and 3.5 , and intervals $0.01,0.001$ or 0.0002 . Schematic representation of the argument range and functional relations provides assistance in reading the tables and in extending the range.

The incomplete elliptic integral of the third kind:

$$
\Pi\left(n, k^{2}, \varphi\right)=\int_{0}^{\varphi}\left(1+n \sin ^{2} x\right)^{-1}\left(1-k^{2} \sin ^{2} x\right)^{-1 / 2} \mathrm{~d} x
$$

depends on three parameters and is correspondingly tiresome to compute and to tabulate. If we are prepared to accept a fairly crude interval for $\varphi$, then Volume 37 gives good information with seven significant figures for the ranges $n=-1 \quad(0.005) \quad-0.98 \quad(0.01) \quad-0.94 \quad(0.02)$ $-0.88(0.03)-0.85(0.05) 0, k^{2}=0(0.01) 1.0, \varphi=0^{\circ}$ (1 $\left.{ }^{\circ}\right) 90^{\circ}$.

When $n=0$, this is a table of the incomplete integral of the first kind, $F^{\prime}\left(k^{2}, \varphi\right)$. Subsidiary tables give:

$$
E\left(k^{2}, \varphi\right)=\int_{0}^{\infty}\left(1-k^{2} \sin ^{2} x\right) \mathrm{d} x
$$

for $k^{2}=0(0 \cdot 01) 1, \varphi=0^{\circ}\left(1^{\circ}\right) 90^{\circ}$, and also various elementary integrals which occur as coefficients in expansions of the elliptic integrals. The second part of the table (not yet published) is to give similar information about II $\left(n, k^{2}, \varphi\right)$ for positive $n$ in the range from 0 to 100 , and the same ranges of $k^{2}$ and $\varphi$.

The Legendre function $P_{n}(x)$ with $n=-\frac{1}{2}+i \tau$ occurs in potential problems when the boundary is a bowl. In Part 1. (Volume 22) tabulation was effected for the range

$$
0 \leqslant \tau \leqslant 50,-0 \cdot 9 \leqslant x \leqslant 0.9 \text {. }
$$

The present Volume 38 is concerned with the range $x>\mathrm{J}$, and in detail gives seven decimal places for:

$$
\begin{aligned}
& x=1 \cdot 1(0 \cdot 1) 2 \cdot 0(0 \cdot 2) 5 \cdot 0(0 \cdot 5) 10 \cdot 0(10) 60, \\
& \tau=0(0 \cdot 01) 50 .
\end{aligned}
$$

These volumes are, of course, highly specialized, but they cope with functions the published tabulation of which has hitherto been inadequate or non-existent. The efficient librarian, if he cannot afford the volumes, will at least make the appropriate notes in the Fletcher, Miller, Rosenhead and Comrie Index. T. A. A. Broadbent

\section{RUSSIAN UNIVERSITY COURSE IN THERMODYNAMICS}

\section{Thermodynamics}

By Prof. I. P. Bazarov. Translated by F. Immirzi. Translation edited by A. E. J. Hayes. Pp. xvi +287. (London and New York: Pergamon Press, 1964.) 50s. net. THERMODYNAMICS, which is by the professor of statistical physics at the Moscow State University, is the first part (it is said in the preface) of a course on thermodynamics and statistical physics as given in the physical and physico-mathematical faculties of the Soviet universities. As such it is emphatically a physicists', rather than a chemists' or engineers' thermodynamies, and it is in the fine tradition of physical thermodynamics and statisties exemplified by an earlier Russian text translated into English, the well-known one by Landau and Lifshitz.

As also in that invaluable Statistical Physics, the illumination of thermodynamics by use of problems is 